\title{
A histopathologic study of urinary bladder tumors at tertiary care center in Mid-Western region of Nepal
}

\author{
Binita Goyal', Sheshagiri Rao ${ }^{2}$, Rajina Sahi ${ }^{3}$, Subechhya Jaiswal ${ }^{4}$ \\ ${ }^{1,3}$ Consultant, ${ }^{2}$ Professor and HOD, ${ }^{4}$ Resident, Department of Pathology, College of Medical Sciences and Teaching \\ Hospital, Bharatpur
}

Background: Urinary bladder cancer is an important cause of morbidity and mortality due to urological conditions. It is tenth most common cancer overall in both sexes. It is seventh most common cancer overall and second most common cancer of genitourinary tract in males. Ninety five percent of bladder tumors are epithelial and the rest are mesenchymal, of which majority are primary urothelial tumors. Urothelial tumors are classified into infiltrating urothelial carcinoma with its variants and non-invasive urothelial neoplasias. Tumor stage is the strongest prognostic parameter. Aims and Objectives: The current study was designed with an aim to elucidate the histologic pattern of bladder tumors and observe whether any association between histologic grade and muscle invasion exists. Materials and Methods: This descriptive study was carried out on 84 cases of urinary bladder tumors received in Department of Pathology, College of Medical Sciences and Teaching Hospital during a time period of 5 years from January 2012 to December 2016. Results: The mean \pm SD of age of presentation was $63 \pm 13$ years with a male female ratio 3.2:1. Ninety-five percent cases were primary epithelial tumors and $93 \%$ cases were of urothelial origin. Low grade papillary urothelial carcinoma was the most common urothelial tumor $(40.5 \%)$ followed by high grade papillary urothelial carcinoma $(34.5 \%)$. Some rare types like primary adenocarcinoma and small cell carcinoma were also seen in this study $(1.2 \%$ each). Muscle invasion was significantly higher in high grade $(66 \%)$ as compared to low grade papillary urothelial carcinoma (3\%). Muscle tissue was absent in $8(9.5 \%)$ cases. Conclusion: There is relationship of histologic grade with aggressiveness of tumor. Most of the high grade tumors are muscle invasive at presentation. Submission of muscle tissue is important for optimal patient management.

Key words: Urinary bladder; bladder tumor; urothelial tumor

\section{INTRODUCTION}

Lesions of urinary bladder are responsible for significant morbidity and mortality throughout the world. ${ }^{1}$ Bladder cancer is the tenth most common cancer overall in both sexes with 430,000 new cases diagnosed in the year 2012 worldwide. It is seventh most common cancer overall and second most common cancer of genitourinary tract in males. ${ }^{2}$ In Nepal, it is fourth most common cancer in males. ${ }^{3} \mathrm{It}$ is three times more common in males than females worldwide with $80 \%$ cases occurring in between 50 to 80 years age group. ${ }^{4}$ Prevalence of bladder tumors is six times higher in developed as compared to developing countriesand is higher in urban areas than rural areas. ${ }^{4,5}$

The most common presenting problem of bladder cancer is painless hematuria. ${ }^{4,6}$ Other symptoms may be dysuria, urgency, frequency, palpable pelvic mass or weight loss and bone pain in advanced disease. Various imaging modalities like ultrasonography, intravenous urography, computed tomography and magnetic resonance imaging can be used for detection and staging. ${ }^{5}$ Diagnosis can be confirmed by cystoscopic examination. ${ }^{1,5}$ However, cystoscopic examination has a limited role in staging process for which transurethral 
resection (TURB) of visible tumor down to the base is required which can accurately assess depth of tumor invasion. ${ }^{7,8}$

Ninety-five percent of bladder tumors are epithelial and the rest are mesenchymal. Urothelial tumors account for approximately $90 \%$ cases of primary urinary bladder tumors. These range from benign, innocuous lesions that do not recur to aggressive tumors that can be fatal. ${ }^{4,}, 10$ The ISUP/WHO (2004) classify urothelial tumors into infiltrating urothelial carcinoma with its variants and non-invasive urothelial neoplasias. The latter is further subclassified into urothelial carcinoma in situ, papillary urothelial carcinoma, high grade and low grade, papillary urothelial neoplasm of low malignant potential (PUNLMP), urothelial papilloma and inverted urothelial papilloma. ${ }^{5}$

There are several clinical and morphological prognostic factors for bladder tumors like patient age, topography of the lesion, multifocality, tumor size, growth pattern, concurrent dysplasia/carcinoma in situ, histologic type, grade and tumor stage., ${ }^{4,11}$ Strongest of these is tumor stage for prognosis and treatment. ${ }^{5,10-13}$

This study was aimed to elucidate the histomorphological profile of bladder tumors in this region of Nepal and correlate its histological grade with muscle invasion.

\section{MATERIALS AND METHODS}

This Hospital record based cross-sectional study (historical)was carried out in Department of Pathology, College of Medical Sciences and Teaching Hospital. Ethical approval from the Institutional Review Committee was obtained. Eighty-four consecutive cystoscopic biopsies, TURBT specimens and radical cystectomies received in the Histopathology section of Department of Pathology of College of Medical Sciences and Teaching Hospital during a time period of 5 years from January 2012 to December 2016 diagnosed with bladder tumor were included in the study. Suboptimal biopsies with crushing artefacts were excluded from the study. All the cases of urinary bladder tumors received in the study period were reviewed.WHO(2004)/ISUP classification was used to classify bladder tumors. ${ }^{5}$ Data was analyzed with SPSS 16. Presence of muscle tissue was noted in the cystoscopic biopsies and TURBT specimens. Association between muscle invasion and histologic grade was tested using Chi-square test. Level of significance was considered as 5\%.

\section{RESULTS}

Total 84 cases of urinary bladder tumors were received in the study period. Age of the patients ranged from 22 to 87 years with maximum cases $25(30 \%)$ in more than 70 years age group. The mean \pm SD of age was $63 \pm 13$ years. There were $64(76 \%)$ males and $20(24 \%)$ females with male to female ratio 3.2:1.

Histopathological diagnoses made were urothelial dysplasia in $1(1.2 \%)$, urothelial papilloma (Figure 1) in $4(4.8 \%)$, inverted urothelial papilloma (Figure 2) in $1(1.2 \%)$, PUNLMP (Figure 3, 4) in $9(10.7 \%)$, low grade urothelial carcinoma (Figure 5, 6) in 34 (40.5\%), high grade urothelial carcinoma (Figure 7,8$)$ in $29(34.5 \%)$, adenocarcinoma (Figure 9) in $1(1.2 \%)$, small cell carcinoma (Figure 10) in $1(1.2 \%)$ and secondaries from other sites in $4(4.8 \%)$ cases (Table 1).

Out of 34 cases of low grade urothelial carcinoma, 18 (53\%) were non-invasive, $12(35 \%)$ showed lamina propria

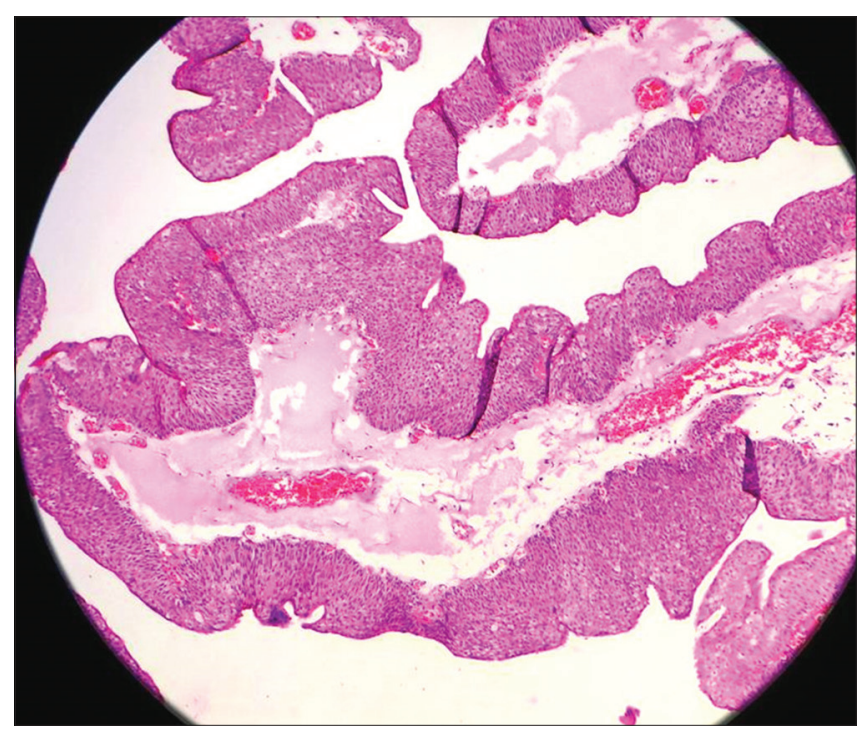

Figure 1: Urothelial papilloma ( $\mathrm{H}$ and E X100)

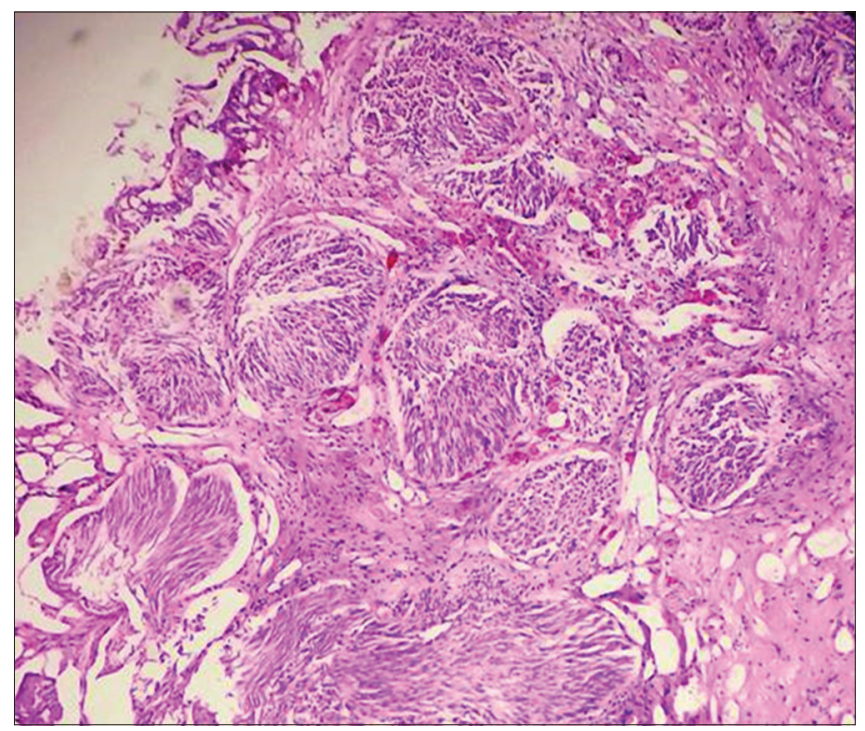

Figure 2: Inverted urothelial papilloma (H and E X100) 


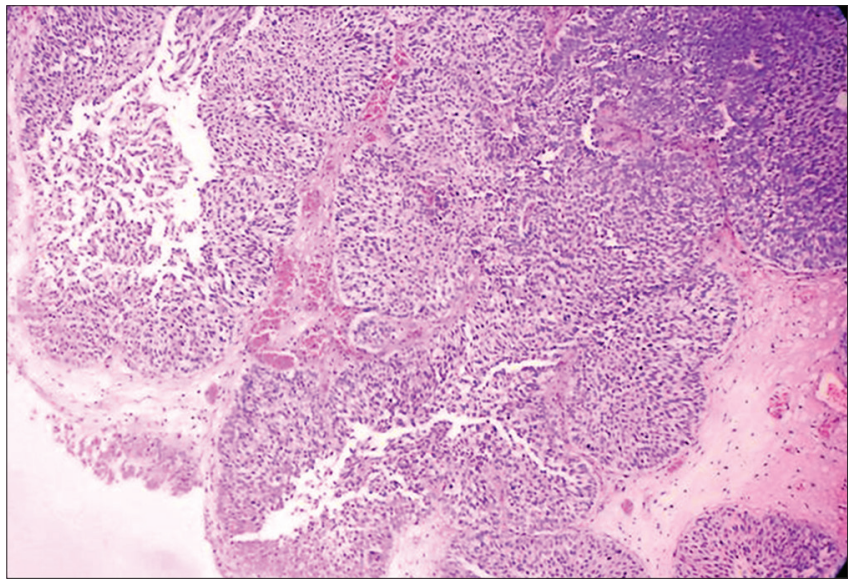

Figure 3: PUNLMP (H and E X100)

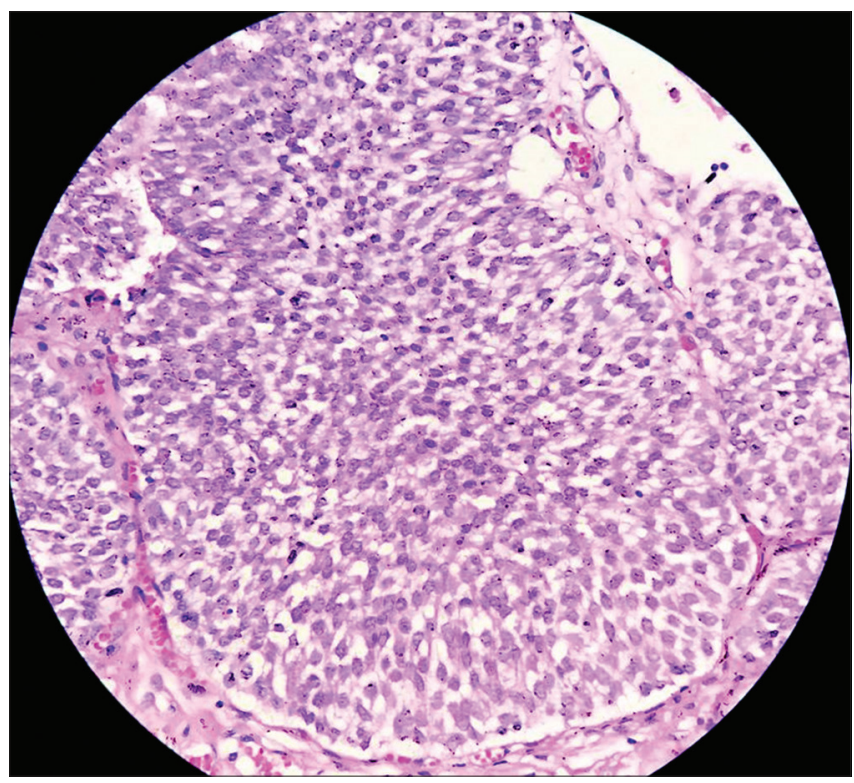

Figure 4: PUNLMP ( $\mathrm{H}$ and E X400)

invasion, $1(3 \%)$ showed muscle invasion and muscle tissue was not seen in $3(9 \%)$ cases. Out of 29 cases of high grade urothelial carcinoma, 19 (66\%) showed muscle invasion (Figure 11), 5 (17\%) showed lamina propria invasion and $5(17 \%)$ cases had no muscle tissue (Table 2). There was statistically significant association between muscle invasion and histologic grade $\left(\chi^{2}=33.71\right.$, d.f $=1$, p-value $\left.<0.001\right)$.

\section{DISCUSSION}

Urinary bladder neoplasms are a heterogeneous group with different subtypes having varied behavior and outcomes. ${ }^{9}, 14$ More than $95 \%$ tumors are epithelial, out of which majority are of urothelial origin and very few are other histological types. ${ }^{5}$

In this study on 84 cases of urinary bladder tumors, mean age of presentation was 63 years (range 22 to 87 years) which is comparable to other studies. ${ }^{9,10,15}$ Five $(6 \%)$ cases of

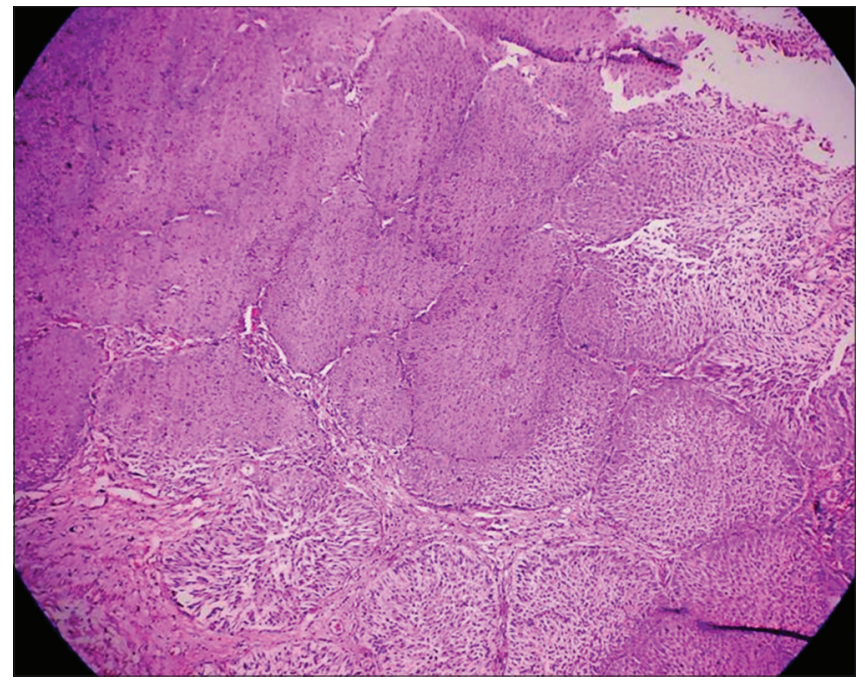

Figure 5: Low grade urothelial carcinoma ( $\mathrm{H}$ and E X100)

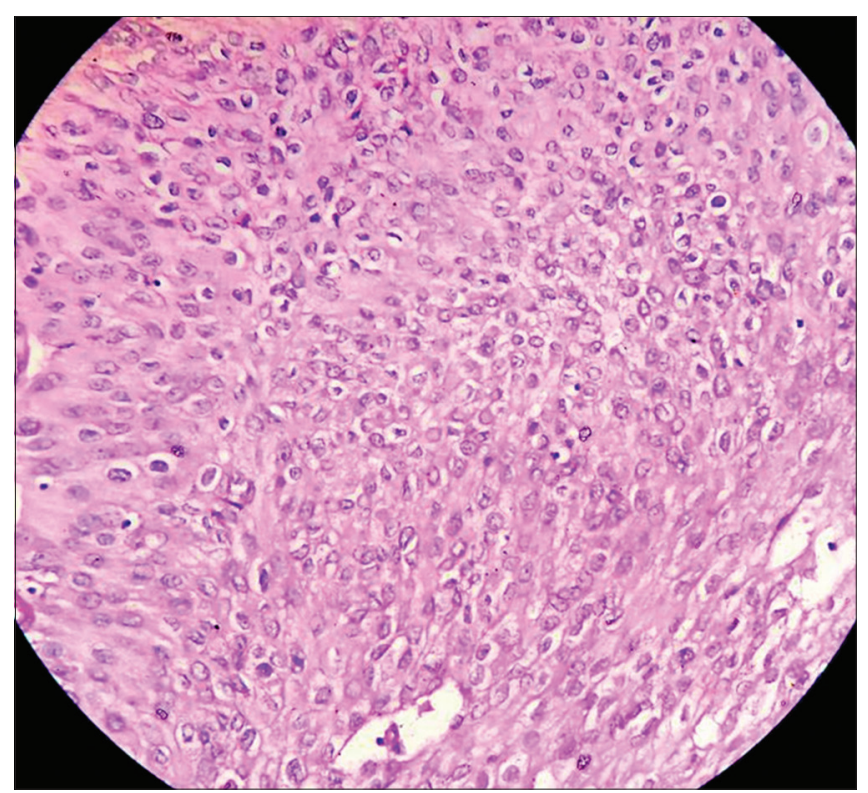

Figure 6: Low grade urothelial carcinoma ( $\mathrm{H}$ and E X400)

bladder tumors were seen in patients younger than 40 years out of which 3 were high grade urothelial carcinoma, 1 was primary adenocarcinoma and 1 was urothelial papilloma. Various literatures state that bladder tumors present at low grade and low stage in younger individuals. ${ }^{16-18}$ However, this was not supported by this study where high grade urothelial carcinoma was more common in younger individuals. Larger sample size is required for conclusive results. Males are more commonly affected. ${ }^{9}, 10,15,16$ This was supported by the present study where male female ratio was 3.2:1. Higher incidence in males may be due to differences in smoking habits and occupational exposure. ${ }^{4,16}$

Primary epithelial tumors were more common in this study $(95.2 \%)$. Secondaries from other sites like cervix (in 3 cases) and colon (in 1 case) were seen in 4 (4.8\%) cases. 


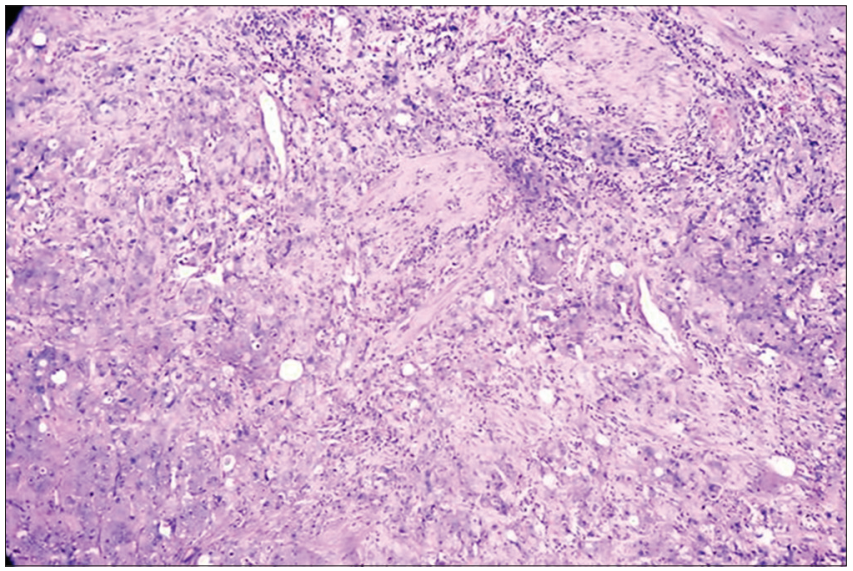

Figure 7: High grade urothelial carcinoma (H and E X100)

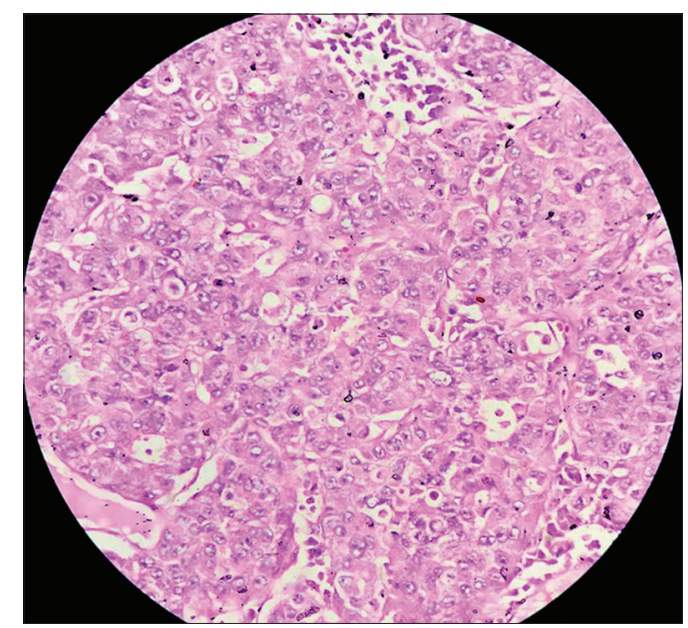

Figure 8: High grade urothelial carcinoma ( $\mathrm{H}$ and E X400)

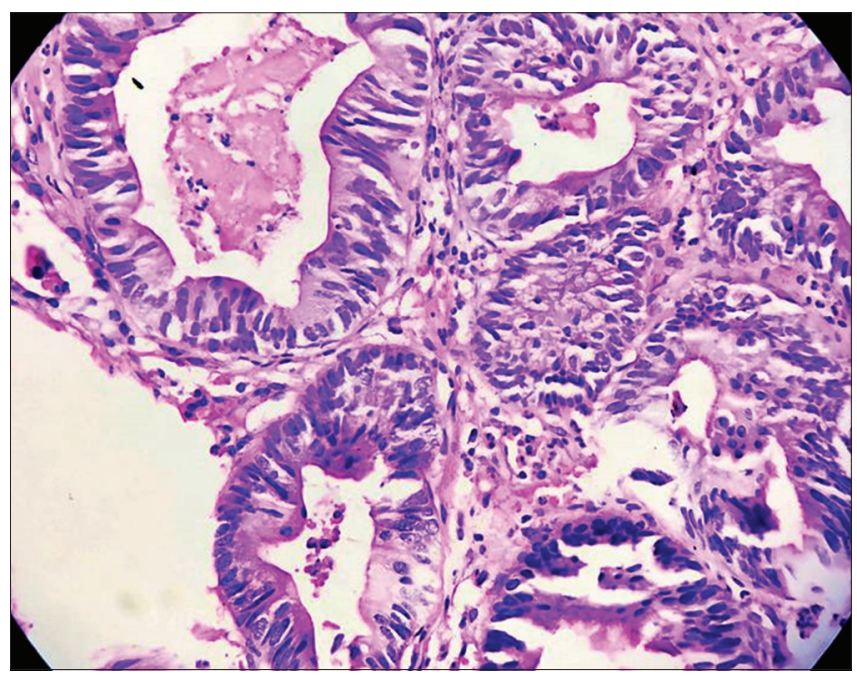

Figure 9: Primary adenocarcinoma of urinary bladder ( $\mathrm{H}$ and E X400)

Ninety-three percent tumors were of urothelial origin. This finding was similar to other studies. ${ }^{9}{ }^{10,15}$ Low grade papillary urothelial carcinoma was the most common urothelial tumor $(40.5 \%)$ in this study which is similar to

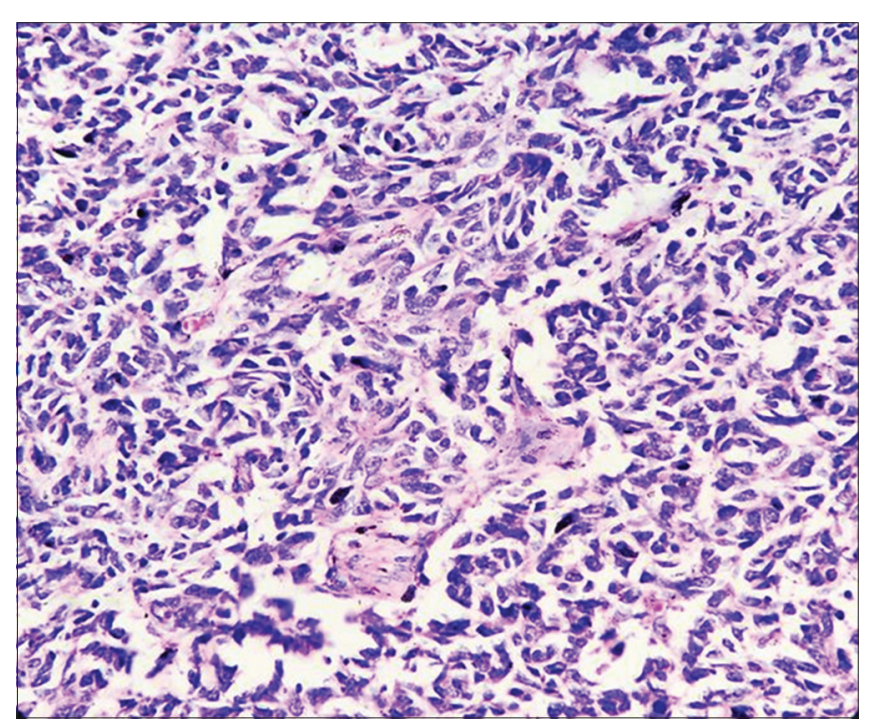

Figure 10: Primary small cell carcinoma of urinary bladder $(\mathrm{H}$ and $\mathrm{E}$ X400)

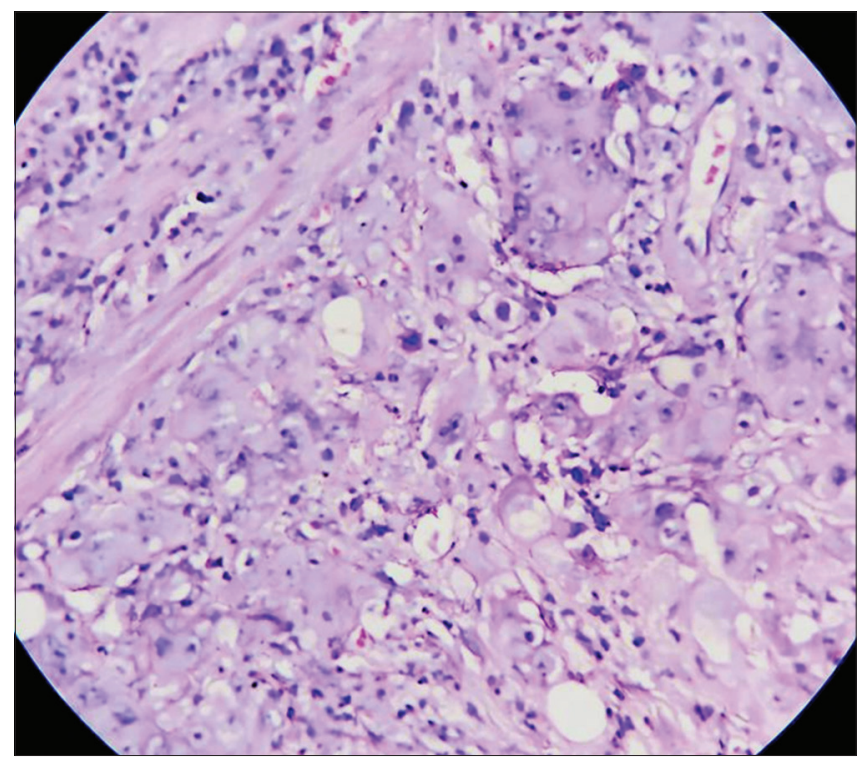

Figure 11: Muscle invasion in high grade urothelial carcinoma $(\mathrm{H}$ and $\mathrm{E}$ $\mathrm{X} 400$ )

findings of Laishram et al. $(2012)^{10}$ and Pudasaini et al. (2014). ${ }^{15}$ However, high grade papillary urothelial carcinoma was more common in study done by Vaidya et al. (2013).? Small cell carcinoma is a rare and aggressive malignancy in urinary bladder and its incidence varies between 0.35 to $1.8 \%$ in various studies. ${ }^{15,19,20}$ Small cell carcinoma was seen in $1(1.2 \%)$ case in this study in a 66 years old male. One case $(1.2 \%)$ was primary adenocarcinoma in a 34 years old male patient. Primary adenocarcinoma is a rare malignancy occurring in urinary bladder with secondary extension from colorectal adenocarcinoma being more common., ${ }^{9}, 21,22$

Most important prognostic parameters are histologic grade and stage of tumor. ${ }^{9}{ }^{23}$ Detection of muscle invasion is 


\begin{tabular}{|c|c|c|c|c|c|c|c|}
\hline \multirow[t]{2}{*}{ S.N } & \multirow[t]{2}{*}{ Histopathological diagnosis } & \multicolumn{5}{|c|}{ Age group (years) } & \multirow[t]{2}{*}{ Total } \\
\hline & & $<40$ & $41-50$ & $51-60$ & $61-70$ & $>70$ & \\
\hline 1. & Urothelial papilloma & 1 & 1 & 0 & 2 & 0 & 4 \\
\hline 2. & Inverted urothelial papilloma & 0 & 0 & 1 & 0 & 0 & 1 \\
\hline 3. & PUNLMP & 0 & 1 & 0 & 3 & 5 & 9 \\
\hline 4. & Low grade urothelial carcinoma & 0 & 4 & 10 & 9 & 11 & 34 \\
\hline 5. & High grade urothelial carcinoma & 3 & 5 & 6 & 7 & 8 & 29 \\
\hline 6. & Adenocarcinoma & 1 & 0 & 0 & 0 & 0 & 1 \\
\hline 7. & Small cell carcinoma & 0 & 0 & 0 & 1 & 0 & 1 \\
\hline 8. & Urothelial dysplasia & 0 & 0 & 0 & 0 & 1 & 1 \\
\hline 9. & Secondaries from other sites & 0 & 2 & 1 & 1 & 0 & 4 \\
\hline Total & & 5 & 13 & 18 & 23 & 25 & 84 \\
\hline
\end{tabular}

\section{Table 2: Level of invasion in histopathological diagnoses}

\begin{tabular}{|c|c|c|c|c|c|c|}
\hline \multirow[t]{2}{*}{ S.N } & \multirow[t]{2}{*}{ Histopathological diagnosis } & \multicolumn{4}{|c|}{ Level of invasion } & \multirow[t]{2}{*}{ Total } \\
\hline & & Muscularispropria & Lamina propria & Non-invasive & No muscle tissue & \\
\hline 1. & Urothelial papilloma & 0 & 0 & 4 & 0 & 4 \\
\hline 2. & Inverted urothelial papilloma & 0 & 0 & 1 & 0 & 1 \\
\hline 3. & PUNLMP & 0 & 0 & 9 & 0 & 9 \\
\hline 4. & Low grade urothelial carcinoma & 1 & 12 & 18 & 3 & 34 \\
\hline 5. & High grade urothelial carcinoma & 19 & 5 & 0 & 5 & 29 \\
\hline 6. & Adenocarcinoma & 1 & 0 & 0 & 0 & 1 \\
\hline 7. & Small cell carcinoma & 1 & 0 & 0 & 0 & 1 \\
\hline 8. & Urothelial dysplasia & 0 & 0 & 1 & 0 & 1 \\
\hline 9. & Secondaries from other sites & 4 & 0 & 0 & 0 & 4 \\
\hline Total & & 26 & 17 & 33 & 8 & 84 \\
\hline
\end{tabular}

of paramount importance because of its influence on therapy and prognosis. ${ }^{24}$ Muscle invasion was significantly seen more in cases of high grade urothelial carcinoma as compared to low grade urothelial carcinoma (66\% versus $3 \%)$. This finding is also seen in various other studies in literature supporting correlation of histologic grade with aggressiveness of tumor. ${ }^{9,10,15}$ Muscle tissue was absent in $8(9.5 \%)$ cases. This emphasizes the need of submission of muscle tissue for optimal patient management.

\section{CONCLUSION}

Bladder tumors are important urological conditions. Primary epithelial malignancies are more common. Urothelial tumors are the most common bladder tumors. Though rare, other primary epithelial malignancies can also present in urinary bladder. More than $50 \%$ of high grade urothelial carcinomas were found to be muscle invasive at presentation suggesting correlation of histologic grade with aggressiveness.

\section{REFERENCES}

1. Srikousthuba, Sukesh, CVR, Hingle S. Profile of lesions in cystoscopic bladder biopsies: a histopathological study. J Clin Diagn Res 2013;7(8):1609-1612.

2. Ferlay J, Soerjomataram I, Dikshit R, Eser S, Mathers C, Rebelo $\mathrm{M}$, et al. Cancer incidence and mortality worldwide: sources, methods and major patterns in GLOBOCAN 2012. Int J Cancer 2015;136(5):E359-E386.

3. Poudel KK, Huang Z, Neupane PR, Steel R and Poudel JK. Hospital-Based Cancer Incidence in Nepal from 2010 to 2013. Nepal J Epidemiol 2017;7(1):659-665.

4. Epstein JI. The Lower Urinary Tract and Male Genital System. In: Kumar V, Fausto N, Aster JC, Abbas AK, editors. Robbins and Cotran Pathologic basis of disease. 8th ed. Philadelphia: Elsevier; 2010. pp.974-981.

5. Tumors of the Urinary System. In: Eble JN, Sauter G, Epstein JI, Sesterhenn IA, editors. Pathology and Genetics of Tumors of the Urinary System and Male Genital Organs. 4th ed. Lyon: IARC press; 2004. pp.89-154.

6. Varkarakis MJ, Gaeta J, Moore RH and Murphy GP. Superficial bladder tumor. Aspects of clinical progression. Urology 1974;4(4):414-420.

7. Satoh E, Miyao N, Tachiki $\mathrm{H}$ and Fujisawa $\mathrm{Y}$. Prediction of muscle invasion of bladder cancer by cystoscopy. EurUrol 2002;41(2):178-181.

8. Cina SJ, Epstein JI, Endrizzi JM, Harmon WJ, Seay TM and Schoenberg MP. Correlation of cystoscopic impression with histologic diagnosis of biopsy specimens of the bladder. Hum Pathol 2001;32(6):630-637.

9. Vaidya S, Lakhey M, K CS and Hirachand S. Urothelial tumours of the urinary bladder: a histopathological study of cystoscopic biopsies. J Nepal Med Assoc 2013;52(191):475-478.

10. Laishram RS, Kipgen $P$, Laishram $S$, Khuraijam $S$ and Sharma DC. Urothelial tumors of the urinary bladder in Manipur: a histopathological perspective. Asian Pac J Cancer Prev 2012;13(6):2477-2479.

11. Angulo Cuesta J, Sanchez Chapado M, Domingue P, Lopez JI, Flores N, Pontes EJ, et al. Prognosis prediction in patients with transitional cell carcinoma of the urinary bladder. Arch EspUrol 
1996;49(4):374-384.

12. Cheng L, Weaver AL, Leibovich BC, Ramnani DM Neumann RM, Scherer BG, et al. Predicting the survival of bladder carcinoma patients treated with radical cystectomy. Cancer 2000;88(10):2326-2332.

13. Droller MJ. Bladder cancer: state-of-the-art care. CA Cancer J Clin 1998;48(5):269-284.

14. Husain NSA, Mekki S, Dawi N and Elsid MA. Clinicopathological Study of Urinary Bladder Neoplasms in Patients at Three Centers in Khartoum, Sudan. Sudan Journal of Medical Science 2009;4(3):259-255.

15. Pudasaini S, Subedi N, Prasad KB, Rauniyar SK, Joshi BR and Bhomi KK. Cystoscopic bladder biopsies: a histopathological study. Nepal Med Coll J 2014;16(1):9-12.

16. Gupta P, Jain M, Kapoor R, Muruganandham K, Srivastava A and Mandhani A. Impact of age and gender on the clinicopathological characteristics of bladder cancer. Indian $\mathrm{J}$ Urol 2009;25(2):207-210.

17. Wan $\mathrm{J}$ and Grossman HB. Bladder carcinoma in patients age 40 years or younger. Cancer 1989;64(1):178-181.

18. Stanton ML, Xiao L, Czerniak BA and Guo CC. Urothelial tumors of the urinary bladder in young patients: a clinicopathologic study of 59 cases. Arch Pathol Lab Med 2013;137(10):1337-1341.

19. Blomjous CE, Vos W, De Voogt HJ, Van der Valk P and Meijer CJ. Small cell carcinoma of the urinary bladder. A clinicopathologic, morphometric, immunohistochemical, and ultrastructural study of 18 cases. Cancer 1989;64(6):1347-1357.

20. Ismaili N. A rare bladder cancer--small cell carcinoma: review and update. Orphanet J Rare Dis 2011;6:75

21. Zhong M, Gersbach E, Rohan SM and Yang XJ. Primary adenocarcinoma of the urinary bladder: differential diagnosis and clinical relevance. Arch Pathol Lab Med 2013;137(3):371-381.

22. Williamson SR, Lopez-Beltran A, Montironi R and Cheng L. Glandular lesions of the urinary bladder:clinical significance and differential diagnosis. Histopathology 2011;58(6):811-834.

23. Matalka I, Bani-Hani K, Shotar A, Bani Hani O and Bani-Hani I. Transitional cell carcinoma of the urinary bladder: a clinicopathological study. Singapore Med J 2008;49(10): 790-794.

24. Urinary tract-bladder. In: Rosai J, editor. Rosai and Ackerman's Surgical Pathology. 10th ed. New delhi: Elsevier; 2011. pp.1247-1286.

\section{Authors Contribution:}

BG - Concept and design of the study, manuscript preparation, statistically analyzed and interpreted,critical revision of the manuscript; TSR - Concept and design of the study, critical revision of manuscript and review of the study; RS - reviewed the literature, helped in preparing first draft of manuscript, collected data; SJ - collected data, statistically analyzed and interpreted, helped in preparing first draft of manuscript.

Work attributed to

College of Medical Sciences and Teaching Hospital, Bharatpur

Orcid ID:

Dr.BinitaGoyal - (10) http://orcid.org/0000-0002-1219-8451

Source of Support: College of Medical Sciences and Teaching Hospital, Bharatpur, Conflict of Interest: None declared. 